\title{
Optimalisasi Superego dalam Teori Psikoanalisis Sigmund Freud untuk Pendidikan Karakter
}

\author{
Hengki Wijaya \\ Sekolah Tinggi Filsafat Jaffray Makassar \\ hengkilily1988@gmail.com \\ I Putu Ayub Darmawan \\ Sekolah Tinggi Teologi Simpson Ungaran \\ putuayub.simpson@gmail.com
}

\begin{abstract}
Abstrak
Teori psikoanalisis Sigmund Freud dikenal karena memperkenalkan ego, superego dan id dalam diri manusia. Sekalipun banyak kontroversi atas teori ini, tetapi kenyataannya masih digunakan dalam dunia pendidikan. Superego dan id digambarkan sebagai alam bawah sadar seumpama bagian gunung es yang tidak terlihat. Keduanya lebih besar dari ego yang tampak di permukaan. Masalahnya apabila id sama dengan ego maka superego sama dengan nol. Artinya superego tidak berfungsi. Dengan demikian amoral, dan kejahatan akan lebih mudah muncul dalam perbuatan manusia. Tulisan ini bertujuan untuk mengoptimalkan superego dalam teori Sigmund Freud dalam pendidikan karakter. Apabila superego lebih besar daripada id maka dipastikan ego sama dengan superego. Pendekatan yang digunakan untuk argumen tulisan ini adalah kualitatif deskriptif dengan pendekatan literature review. Kajian yang menggunakan sumber literatur yang berhubungan dengan teori psikoanalisis dan pemanfaatannya dalam pendidikan karakter. Hasilnya adalah pendekatan teori Sigmund Freud dalam pendidikan karakter dengan optimalisasi superego dapat mencegah potensi id berkembang dalam diri manusia. Superego yang terdiri atas penguatan karakter, moral, kasih, dan spiritual dapat menahan perkembangan id dalam diri seseorang untuk mewujudkan dalam perbuatan (ego). Optimaslisasi superego ini dapat diterapkan dalam pendidikan dasar sejak dini untuk penguatan pendidikan karakter di Indonesia.
\end{abstract}

Kata-kata kunci: supergo, id, ego, karakter, Sigmud Freud

\section{Pendahuluan}

Penulis mulai mengenal Sigmund Freud melalui teori psikoanalisis yang dikenal sebagai tokoh penemu psikoanalisisyang kontroversial dengan hasil temuannya. Sigmund Freud memberikan pandangan yang berbeda tentang manusia dan perilakunya. Bagi Freud manusia itu adalah makhluk yang berenergi dimana keseluruhan perilakunya ditentukan oleh zona ketidaksadaran manusia. Ketidaksadaran itu dikenal sebagai alam bawah sadar.

Teori psikoanalisis ini terdiri atas Id, Ego, dan Superego. Freud menggambarkannya seperti gunung es dimana yang tamak di permukaan adalah Ego yang prinsipnya adalah kenyataan yang terjadi pada kehidupan manusia. Namun hal tersebut hanyalah sebagian kecil yang tampak. Hal yang terbesar yang tidak tampak adalah ketidaksadaran yang bagi Freud disebut Id dan Superego. 
Freud bagian terbesar dalam pikiran seseorang adalah alam bawah sadar. Bagian ini seperti nafsu, insting dan segala sesuatu yang masuk di dalamnya dan sulit dijangkau, seperti kenangan atau emosi traumatik. Freud menyatakan bahwa alam bawah sadar adalah sumber motivasi dan dorongan terhadap hasrat seseorang, baik yang sederhana, seperti makan, seks, maupun kreativitas seperti berkarya (Ahmad, 2017:283).

Ego adalah bagian kepribadian yang bertugas menilai realitas dan berhubungan dengan dunia dalam untuk mengatur dorongan-dorongan id agar tidak melanggar nilai-nilai superego. Sedang superego adalah bagian moral dari kepribadian manusia, karena ia merupakan filter, alat sensor yang menentukan sesuatu itu baik- buruk, atau salah-benar (Ahmad, 2017:294). Ego adalah perbedaan antara sensasi dari dalam dan persepsi dari luar; istilah yang digunakan dalam psikoanalisis adalah bahwa anak telah belajar untuk 'menguji realitas'. Dengan demikian hal ini sangat bergantung dominasi yang terjadi pada alam bawah sadar antara Id dan Superego. Bila Id sudah menjadi hal biologis manusia dan bersifat bawaan maka tentunya yang diungkapkan oleh Freud bahwa Superego adalah pengendali das Es (Id) adalah benar adanya. Fungsi Superego yang utama adalah mengarahkan Id dan Ego ke arah yang lebih bermoral.

Freud juga mengungkapkan bahwa Ego memiliki pertahanan yang dapat mencegah dorongan kuat Id (nafsu, insting, dan kebutuhan biologis) muncul di permukaan maupun tekanan Superego sendiri terhadap Ego (Kuntojo, 2015:46). Dalam praktiknya, hal tersebut dapat terjadi. Sebagai contoh, peserta didik memiliki benih kebaikan dan kejahatan. Ego peserta didik dapat membedakan apa yang baik, dan jahat. Namun lingkungan sekitarnya, dan pikirannya didominasi oleh kejahatan maka pertahanan ego dapat dilewati dengan mudah oleh dorongan Id. Maka fungsi Superego terabaikan dengan sendirinya. Peserta didik akan melakukan perbuatan amoral pada alam sadarnya yaitu kenyataan yang terjadi di permukaan.

Kaitannya untuk pendidikan karakter peserta didik adalah melakukan penguatan pendidikan karakter pada ranah alam bawah sadar dengan melakukan optimalisasi Superego yang terus-menerus ditinkatkan dalam proses pembelajaran baik dalam keluarga, sekolah, dan masyarakat. Hal yang berulang-ulang dilakukan akan membentuk ingatan yang sifatnya tetap dalam alam bawah sadar. Bila sumber Id yang terus meningkat di alam bawah sadar maka kecenderungan yang meningkat adalah hal-hal yang negatif. Namun bila integrasi pendidikan karakter dapat dilakukan secara holistik (kognitif, afektif, dan psikomotorik).

Tulisan ini menjadi penting saat ini karena adanya krisis moral yang ditunjukkan oleh oknum masyarakat yang terstruktur, sistematis, dan masif. Hal itu akan memengaruhi 
dominasi Superego terhadap Id di alam bawah sadar. Jiwa manusia yang terdiri atas pikiran, perasaan dan kehendak telah menguasai alam bawah sadar manusia. Oleh karena itu diperlukan pengendalian diri melalui pemahaman, perasaan dan tindakan yang bermoral untuk melawan jiwa yang amoral tersebut. Hal yang bermoral dapat bersumber pada kebenaran agama, perilaku moral, etis, adat istiadat, dan kebiasaan yang baik. Kebiasaan yang baik mengalahkan kebiasaan yang buruk. Lingkungan yang positif mendukung pertumbuhan karakter yang matang dan bermoral.

Asumsi argumen ini adalah optimalisasi Superego di alam bawah sadar sebagai pengendali Id yang sebelumnya lebih berotoritas dan berpengaruh sehingga lebih mudah menerobos pertahanan Ego dan muncul di permukaan. Tulisan ini bertujuan untuk mengoptimalkan Superego dalam teori Sigmund Freud dalam pendidikan karakter. Apabila Superego lebih besar daripada Id maka dipastikan Ego sama dengan Superego. Pendekatan yang digunakan untuk argumen tulisan ini adalah kualitatif deskriptif dengan pendekatan literature review. Kajian yang menggunakan sumber literatur yang berhubungan dengan teori psikoanalisis dan pemanfaatannya dalam pendidikan karakter. Hasil luaran dalam tulisan ini memberikan modifikasi alam bawah sadar yang lebih didominasi atau dipengaruhi oleh Superego dan diberikan penjelasan yang akurat untuk membuktikan bahwa optimalisasi Superego itu dalam dilakukan dalam pendidikan karakter.

\section{Metode}

Metode yang digunakan dalam tulisan ini adalah metode kualitatif deskriptif dengan pendekatan literature review. Tinjauan literatur adalah analisis kritis terhadap sumber yang diterbitkan, atau literatur, pada topik tertentu. Ini adalah penilaian literatur dan memberikan ringkasan, klasifikasi, perbandingan dan evaluasi ("Writing a literature review," 2018).

Tujuan kajian literatur ini adalah menganalisis berbagai penelitian tentang teori psikoanalisis Sigmund Freud terutama yang membahas mengenai Id, Superego, dan Ego. Penulis akan mengumpulkan sumber bacaan dari jurnal-jurnal dan buku-buku yang berkaitan erat dengan topik tersebut. Penulis akan mensintesis beberapa tulisan dan membangun gagasan untuk membuktikan bahwa optimalisasi Superego dalam teori psikoanalisis memungkinkan untuk dilakukan. Selanjutnya diimplikasikan dalam pendidikan karakter. Beberapa ajuan dari sumber primer dan sekunder sebagai arus utama dan alternatif akan mewarnai tulisan ini termasuk di dalamnya kebenaran-kebenaran alkitabiah. 
Penggambaran para peneliti mengenai Id, Superego, dan Ego diberi penekanan pada Superego. Penulis akan mengkaji secara kritis setiap hasil penelitian, dan kesimpulan sumber jurnal untuk menyusun topik yang dikaji.

\section{Hasil dan Diskusi}

Konsep Pembentukan Kepribadian Freud

Dalam konsep Freud, manusia dianggap memiliki sebuah energi psikis yang mendorong manusia untuk berperilaku dan sifatnya dinamis. Wiraatmadja (2003:31) menjelaskan bahwa sumber energi tersebut adalah Id, Ego, dan Superego, serta disebut sebagai teori kepribadian psikoanalisis. Konsep tersebut disebut sebagai teori kepribadian psikoanalisis memiliki peran untuk memodifikasi dan memperkaya perilau atau sikap manusia (Helaluddin, 2018:3). Fungsi dari Id adalah sebagai sumber utama energi yang memungkinkan manusia untuk bertahan hidup, kemudian Ego berfungsi secara logis-rasional yang didasarkan pada prinsip kenyataan dan proses sekunder yang merupakan sebuah proses logis untuk melihat kenyataan dalam upaya untuk menemukan cara memuaskan dorongan Id secara realistis, lalu dalam Superego terdapat nilai-nilai moral yang mewakili nilai-nilai ideal dan memberikan batasan baik dan buruk (Wiraatmadja, 2003:32). Freud (1983:87) mengungkapkan bahwa kebutuhan-kebutuhan jasmani berasal dari rangsangan aktivitas psikis dan yang dicari adalah pemuasan. Menurut Freud, naluri tersebut terdapat dalam Id dan Ego. Konsep perilaku yang digambarkan oleh Freud (1983) adalah Id digambarkan sebagai tenaga yang menggerakkan kapal dan Ego adalah kemudinya. Dalam konsep ini, tugas dari Ego adalah mencegah atau memegang kendali pada Id sehingga naluri-naluri yang ada dalam Id dicegah oleh Ego. Dalam konsep ini Freud memiliki pandangan bahwa tuntutan dari naluri dalam Id akan dikendalikan jika fungsi logis rasional dalam Ego.

Dalam konsep kepribadian Freud, struktur jiwa manusia terdapat tiga tingkatan yaitu alam sadar (conscious mind) yang digunakan dalam keadaan terbangun untuk membuat individu sadar akan situasi lingkungannya dan merespon dengan cepat, alam pra-sadar (preconscious mind), dan alam tak-sadar (unconscious mind) yang mengandung pengalaman dan ingatan yang telah dipelajari pada masa lalu serta semua tingkah laku dan refleksi yang dipelajari (Ahmad, 2017; “Understanding Hypnotherapy," n.d.). Konsep tersebut digambarkan sebagai sebuah gunung es yang terapung yang pada bagian permukaan atau yang muncul ke permukaan air adalah adalah alam sadar dan yang tenggelam adalah alam tak sadar. Kekuatan yang tidak tampak dalam permukaan seperti kekuatan irasional, kekuatan 
alam bawah sadar, dorongan biologis, serta insting yang terbentuk sebelum usia 6 tahun membentuk perilaku manusia (Helaluddin \& Syawal, 2018; McLeod, 2016).

Gambar 1. Gambaran Id, Ego, dan Superego

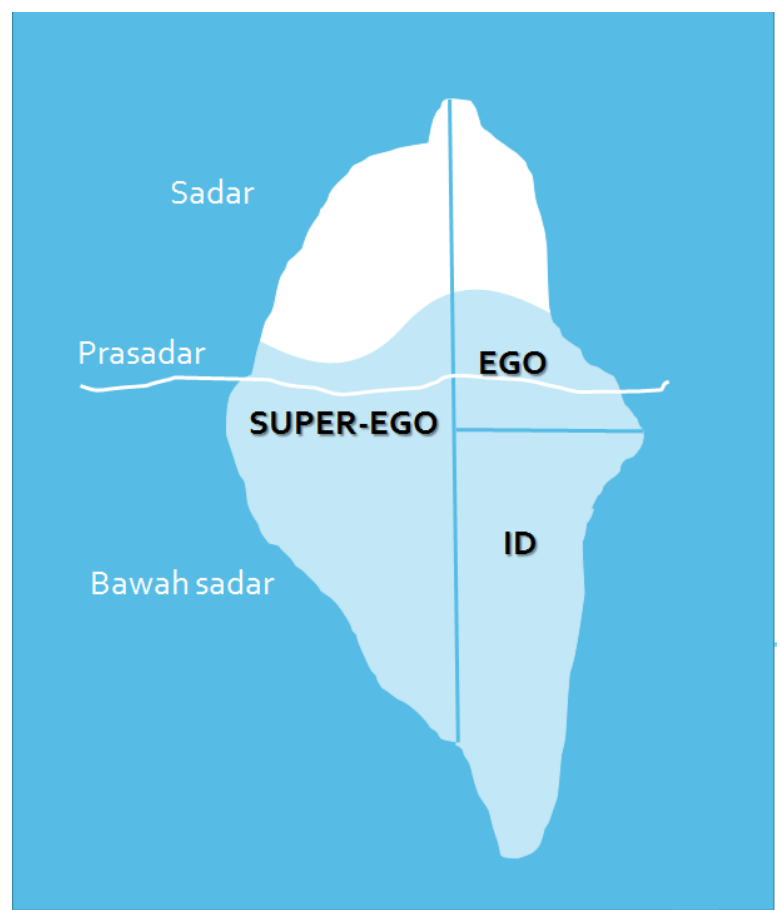

Ahmad (2017) menjelaskan bahwa menurut Freud dalam alam bawah sadar terdapat hal-hal yang sulit untuk dibawa ke alam sadar, tetapi sumber-sumber dalam alam bawah sadar tersebut menjadi sumber motivasi yang mendorong hasrat seseorang. Sumber-sumber yang berada di bawah alam sadar seperti nafsu, insting, kenangan, atau emosi traumatik sulit untuk dijangkau dan tampak, tetapi sumber-sumber tersebut menjadi pendorong untuk manusia bertindak seperti makan, berinovasi, melakukan hubungan seks, dan berbagai tindakan lainnya.

\section{Memaksimalkan Superego Dalam Pendidikan Karakter}

Jika dalam konsep Freud, tuntutan dari naluri dalam Id akan dikendalikan jika fungsi logis rasional dalam Ego, sementara bagi penulis tuntutan naluri dalam Id diperkecil dengan memperbesar Superego. Superego tidak bisa membungkus Id, yang dapat dilakukan adalah memperkecil ruang gerak dari Id sehingga Superego lebih besar daripada Id.

McLeod (2016) menjelaskan bahwa dalam Superego digabungkan nilai-nilai dan moral masyarakat yang dipelajari dari orang tua dan orang lain. Nilai-nilai tersebut diperoleh dan berkembang pada usia 3 hingga 5 tahun. Menurut McLeod (2016) dalam Superego terdapat dua sistem yaitu hati nurani yang akan berfungsi untuk menghukum Ego melalui 
perasaan bersalah dan ego-ideal merupakan gambaran imajiner tentang bagaimana individu itu seharusnya, baik tentang karier, sikap terhadap orang lain, serta bagaimana individu tersebut berperilaku sebagai anggota masyarakat. Dalam konsep Freud ini, McLeod mencontohkan jika ego menyerah pada tuntutan id, maka superego dapat membuat orang tersebut merasa buruk melalui rasa bersalah.

Hartmann \& Loewenstein (1962:78) menjelaskan bahwa setiap sistem nilai moral mewakili tuntutan ideal atau menjadi arahan ideal Ego. Nilai-nilai yang telah ditanamkan kemudian menghasilkan perbedaan individu setelah usia tersebut. Lebih lanjut dijelaskan bahwa perkembangan individu setelah masa remaja mengalami perbedaan ketika dibandingkan saat usia anak-anak. Dengan diperkuatnya Superego maka dapat mendorong tampilnya karakter yang lebih baik. Sesuai dengan pendapat McLeod (2016) yang menjelaskan bahwa Superego berfungsi untuk mengendalikan implus Id seperti naluri-naluri yang bertentangan atau dilarang oleh masyarakat, misalnya perilaku seks yang menyimpang, agresi terhadap orang lain, dan naluri negatif lainnya, maka dapat membujuk ego agar beralih ke tujuan-tujuan moralistik serta berjuang untuk menuju kesempurnaan. Groot (1962) menjelaskan bahwa Superego diperlukan untuk hidup dalam masyarakat. Nilai-nilai moral yang telah tertanam pada masa anak-anak yang menjadi seperti "bekal" yang kemudian mempengaruhi perilaku setelah masa anak-anak.

Gambar 2. Superego yang dimaksimalkan

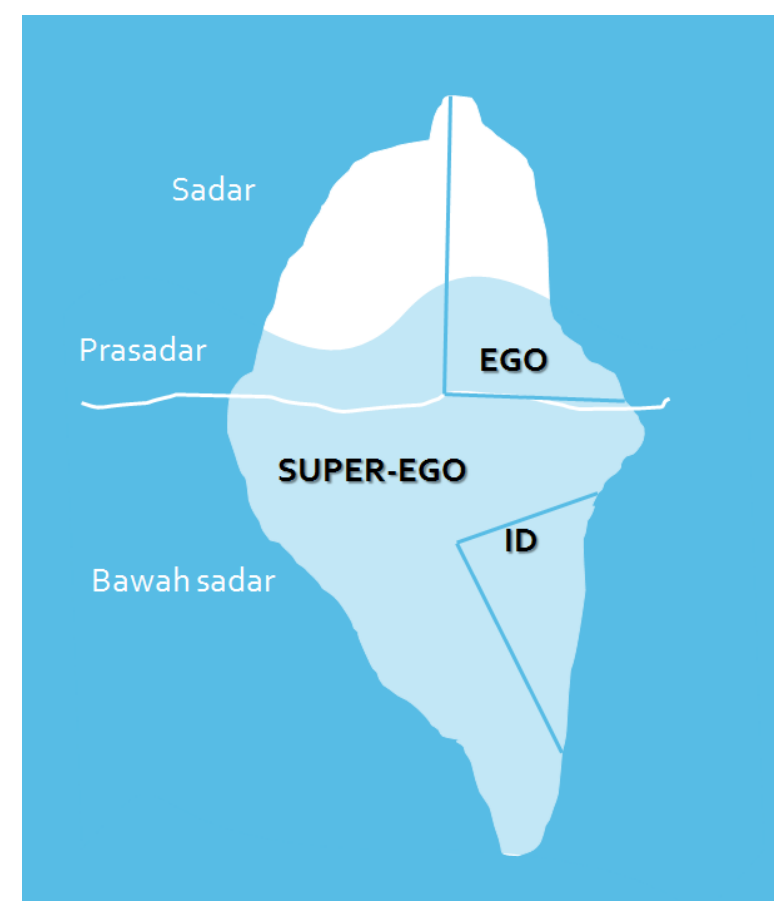

Mengacu pada pendapat McLeod (2016) untuk memaksimalkan Superego maka pendidikan karakter harus dimulai sebelum usia usia 5 tahun dan terdapat peran orangtua 
serta masyarakat yang berada di sekitar anak-anak. Penanaman nilai-nilai moral dimulai oleh orangtua dan orang lain yang berada disekitar anak. Orangtua menanamkan nilai-nilai moral yang akan menjadi ego-ideal sehingga mereka memiliki gambaran imajiner tentang karier, sikap terhadap orang lain, serta sikap sebagai anggota masyarakat. Orangtua dapat melakukan proses pembelajaran memorisasi dengan menanamkan nilai-nilai moral pada anak. Darmawan (2019) menjelaskan bahwa proses pembelajaran memorisasi yang dilakukan oleh orang Yahudi seperti tercatat dalam Ulangan 6:6-9 menghasilkan generasi yang perilakunya dipengaruhi oleh nilai-nilai yang telah ditanamkan pada masa anak-anak. Mengacu pada definisi Wijaya \& Tulak (2019), pendidikan karakter merupakan sebuah proses yang disadari dan disengaja, proses tersebut dilakukan untuk memampukan individu menerapkan perilaku kebajikan bagi dirinya sendiri, dan bagi orang lain. Dalam proses ini, orangtua berperan melakukan sebuah proses yang dilakukan secara sengaja dan disadari sehingga dalam diri anak-anak tertanam nilai-nilai moral, yang pada akhirnya mereka mampu menerapkan perilaku kebajikan bagi dirinya sendiri dan bagi orang lain. Salah satu cara untuk mengoptimalkan peran Superego dalam pendidikan karakter adalah dengan disiplin rohani. Dengan disiplin rohani yang berkaitan erat dengan nilai-nilai moral dapat membentuk superego yang kuat.

Bagi masyarakat Indonesia yang akan memasuki era masyarakat 5.0, keberfungsian keluarga sangat penting. Sumantri (2019) menjelaskan bahwa generasi Y [dan Z] yang hidup diera revolusi industri 4.0 adalah generasi yang berorientasi pada teknologi semata, sehingga ada kecenderungan akan menghasilkan generasi dengan pribadi robotik atau generasi zombie yang egoistik, infantil, dan antisosial. Untuk menghindari apa yang ditakutkan oleh Sumantri maka penguatan Superego harus dilakukan sejak usia dini sehingga tertanam nilai-nilai moral yang mempengaruhi perilaku anak ketika usia dewasa. Bagi Wijaya (2018) pendidikan karakter yang menjamah ranah inner side, mental life, mind affected word, dan geistigewelt adalah opsi yang harus dioptimalkan dalam pendidikan di Indonesia dan sehingga dapat memiliki karakter yang baik untuk hidup dalam masyarakat.

\section{Kesimpulan \& Saran}

Dalam konsep Freud, fungsi Ego adalah untuk mencegah naluri-naluri yang ada dalam Id. Secara umum Id maupun Superego adalah sesuatu yang tidak tampak, tetapi mendorong apa yang kelihatan dipermukaan. Dalam Superego terdapat nilai-nilai moral yang mewakili nilai-nilai ideal dan memberikan batasan baik dan buruk. Nilai-nilai moral tersebut diperoleh dari orangtua maupun orang lain ketika usia 3 hingga 5 tahun. Dengan memiliki 
nilai-nilai moral yang baik, individu memiliki nilai untuk menghukum Ego dan gambaran individu ideal. Orangtua perlu menanamkan nilai-nilai moral tersebut secara berulang-ulang sehingga tertanam dalam ingatan, kemudian mempengaruhi nilai-nilai yang dipegang.

Untuk pembelajaran usia dini, kajian ini dapat diterapkan dalam model pembelajaran, kemudian dapat digunakan dalam memahami peserta didik pada usia dini dan kebutuhan peserta didik sehingga dapat melakukan integrasi nilai-nilai karakter dalam proses pembelajaran di kelas yang sesuai dengan pemahaman. Untuk penelitian lanjutan dapat diteliti pengaruh optimalisasi superego dengan disiplin rohani terhadap pertumbuhan rohani.

\section{Daftar Pustaka}

Ahmad, M. (2017). Agama dan Psikoanalisa Sigmund Freud. RELIGIA, 14(2), 145-318. https://doi.org/10.28918/religia.v14i2.92

Darmawan, I. P. A. (2019). Pembelajaran Memorisasi dalam Ulangan 6:6-9. EPIGRAPHE: Jurnal Teologi dan Pelayanan Kristiani, 3(1), 25-31.

Freud, S. (1983). Sekelumit Sejarah Psikoanalisa. Jakarta: Gramedia.

Groot, J. L.-D. (1962). Ego Ideal and Superego. The Psychoanalytic Study of the Child, 17(1), 94-106. https://doi.org/10.1080/00797308.1962.11822840

Hartmann, H., \& Loewenstein, R. M. (1962). Notes on the Superego. The Psychoanalytic Study of the Child, 17(1), 42-81. https://doi.org/DOI:

$10.1080 / 00797308.1962 .11822838$

Helaluddin, H., \& Syawal, S. (2018). Psikoanalisis Sigmund Freud dan Implikasinya dalam Pendidikan. Retrieved June 17, 2019, from ResearchGate website: https://www.researchgate.net/publication/323535054_Psikoanalisis_Sigmund_Freud_ dan_Implikasinya_dalam_Pendidikan

Kuntojo. (2015). Psikologi perkembangan. Yogyakarta: Diction.

McLeod, S. (2016). Id Ego Superego. Retrieved June 14, 2019, from Simply Psychology website: https://www.simplypsychology.org/psyche.html

Sumantri, D. (2019, February 16). Society 5.0 dalam Perspektif Generasi Milenial. Retrieved June 24, 2019, from Harianjogja.com website: https://opini.harianjogja.com/read/2019/02/16/543/972241/opini-society-5.0-dalamperspektif-generasi-milenial

Understanding Hypnotherapy. (n.d.). Retrieved June 24, 2019, from equilibriumforlife website: http://www.equilibriumforlife.co.uk/what-is-therapy-counselling-analyticalhypnotherapy-life-coaching/understanding-hypnotherapy/ 
Wijaya, H. (2018). Hakikat Pendidikan Karakter. Online] Https://Researchgate. Net.

Wijaya, H., \& Tulak, H. (2019). Pengembangan Model Pembelajaran Pendidikan Karakter Berbasis Media Sosial [Preprint]. https://doi.org/10.31219/osf.io/g68fs

Wiraatmadja, S. (2003). Pengantar Psikologi Umum. Ungaran: STT Simpson.

Writing a literature review. (2018). Retrieved June 4, 2019, from

https://www.citewrite.qut.edu.au/write/litreview.jsp 